\title{
The characteristics of electrical trees in the inner and outer layers of different voltage rating XLPE cable insulation
}

\author{
Ansheng Xie ${ }^{1,2}$, Shengtao $\mathrm{Li}^{1}$, Xiaoquan Zheng ${ }^{1}$ and George Chen ${ }^{3}$ \\ ${ }^{1}$ State Key Laboratory of Electrical Insulation and Power Equipment, Xi' an Jiaotong University, \\ Xi'an 710049, People's Republic of China \\ ${ }^{2}$ School of Environment Science and Engineering, Chang' an University, Xi' an 710054, \\ People's Republic of China \\ ${ }^{3}$ School of Electronics and Computer Science, University of Southampton, Southampton SO17 1BJ, UK \\ E-mail: sli@mail.xjtu.edu.cn, xieansheng@gmail.com,xqzheng@mail.xjtu.edu.cn and \\ gc@ecs.soton.ac.uk
}

Received 2 December 2008, in final form 13 April 2009

Published 4 June 2009

Online at stacks.iop.org/JPhysD/42/125106

\begin{abstract}
The statistical initiation and propagation characteristics of electrical trees in cross-linked polyethylene (XLPE) cables with different voltage ratings from 66 to $500 \mathrm{kV}$ were investigated under a constant test voltage of $50 \mathrm{~Hz} / 7 \mathrm{kV}$ (the $66 \mathrm{kV}$ rating cable is from UK, the others from China). It was found that the characteristics of electrical trees in the inner region of $66 \mathrm{kV}$ cable insulation differed considerably from those in the outer region under the same test conditions; however, no significant differences appeared in the $110 \mathrm{kV}$ rating cable and above . The initiation time of electrical trees in both the inner and the outer regions of the $66 \mathrm{kV}$ cable is much shorter than that in higher voltage rating cables; in addition the growth rate of electrical trees in the $66 \mathrm{kV}$ cable is much larger than that in the higher voltage rating cables. By using $x$-ray diffraction, differential scanning calorimetry and thermogravimetry methods, it was revealed that besides the extrusion process, the molecular weight of base polymer material and its distribution are the prime factors deciding the crystallization state. The crystallization state and the impurity content are responsible for the resistance to electrical trees.

Furthermore, it was proposed that big spherulites will cooperate with high impurity content in enhancing the initiation and growth processes of electrical trees via the 'synergetic effect'. Finally, dense and small spherulites, high crystallinity, high purity level of base polymer material and super-clean production processes are desirable for higher voltage rating cables.

(Some figures in this article are in colour only in the electronic version)
\end{abstract}

\section{Introduction}

High voltage cross-linked polyethylene (XLPE) cables play an important part in today's power systems, whose reliability and service life largely depend on the tree-like ageing in the insulation layer of cables. In the past several decades, numerous works have been dedicated to the electrical trees in polymers. The characteristics of light emission during the early stages of electrical trees in polyethylene were investigated $[1,2]$. Through the measurement and simulation of electrical tree growth and partial discharge (PD) activity in epoxy resins, various PD models have been established to simulate the PD activity in tree channels and to investigate the relation between PD and trees' propagation [3-10], the effect of externally applied mechanical stress on the electrical tree growth behaviours in polymers $[11,12]$. The fractal and statistical characteristics of electrical treeing have been simulated [13]. In addition to the ageing characteristics of the electrical trees in the XLPE cable insulation, other investigations include the luminescence characteristics before the initiation of electrical trees with elevated temperatures [14], the electrical tree inception phenomena and the analysis 
Table 1. Type and number of tested samples.

\begin{tabular}{lllllllll}
\hline & \multicolumn{8}{c}{ Type } \\
\cline { 2 - 8 } & \multicolumn{1}{c}{$66 \mathrm{kV}$} & \multicolumn{2}{c}{$110 \mathrm{kV}$} & \multicolumn{2}{c}{$220 \mathrm{kV}$} & \multicolumn{2}{c}{$500 \mathrm{kV}$} \\
\hline Position & Inner & Outer & Inner & Outer & Inner & Outer & Inner & Outer \\
Number & 20 & 10 & 8 & 7 & 8 & 9 & 10 & 10 \\
\hline
\end{tabular}

of dominant factors affecting the XLPE cable insulation breakdown under ac operating and lightning impulse voltages using XLPE cable insulation block samples $[15,16]$, the influence of insulation morphology on the electrical treeing [17], the influence of internal residual mechanical stresses on cables' breakdown strength and the initiation and growth characteristics of electrical trees [18, 19]. Laurent and Mayoux [20] have studied electrical tree propagation characteristics by simultaneous measurements of the spatial distribution of the light emitted and the PD current pulses in the external circuit during the growth of trees. It has been found that the propagation rates are very different for bush-type, branch-type and bush-branch-type trees. The differences in the propagation rate are also reflected in light emission and discharge rate. The changeover from large amplitude PD current pulses in the external circuit to much smaller amplitude pulses is associated with a change in the spatial distribution of the PD activity. The higher amplitude PD pulses are correlated with the PD activity occurring from the pin tip into the tree channels whereas the lower magnitude discharges are correlated with the localized discharges occurring at the isolated points in the tree structure and at the growing tree tips.

Harlin et al [17] studied the propagation characteristics of electrical trees in $220 \mathrm{kV}$ XLPE cables insulation and suggested that insulation morphology has a great influence on the initiation voltage, while its effects on propagation and statistical characteristics of electrical trees for different high voltage rating XLPE cables insulation have not been considered yet. In our previous papers, the propagation characteristics of electrical trees in both the inner and the outer layers of the $66 \mathrm{kV}$ XLPE cable insulation [21,22] have been compared, which indicates that the morphology, the structure and the growth characteristics of electrical trees are very different between the inner and the outer regions of the XLPE cable insulation. It was also suggested that the propagation characteristics have a close relationship with the morphology of the material. In this paper we extend our research to higher rating cables and a series of treeing experiments on samples from $66,110,220$ and $500 \mathrm{kV}$ cables has been performed under power frequency, in which special attention has been paid to the comparison of structure and growth characteristics of electrical trees in both the inner and the outer regions of the XLPE cables insulation.

\section{Sample preparation and experimental set-up}

\subsection{Sample preparation}

The samples were taken from a $66 \mathrm{kV}$ high voltage XLPE cable supplied by a UK cable manufacturer and from 110, 220 and $500 \mathrm{kV}$ high voltage XLPE cables supplied by the Qingdao

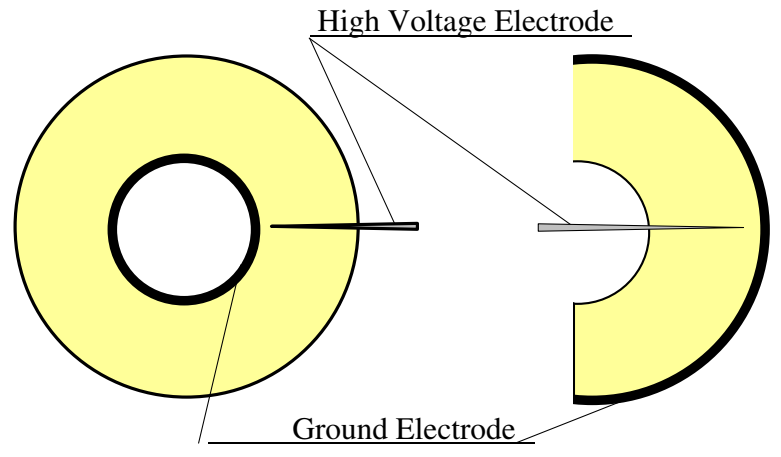

(a) inner layer

(b) outer layer

Figure 1. Samples configuration.

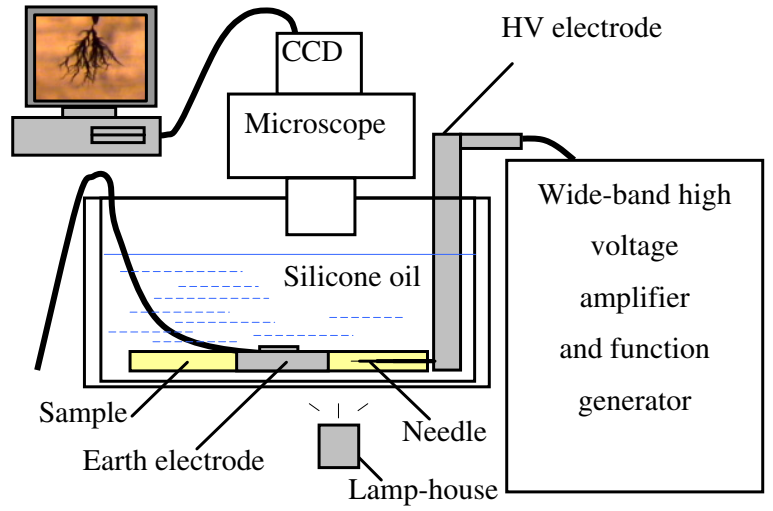

Figure 2. The experimental set-up for the electric treeing test.

Hanlan Cable Company of China. The type and number of tested samples are listed in table 1 . The cable insulation was cut into hollow and semicircle disc shape with a thickness of $5 \mathrm{~mm}$ (figure 1). The samples for treeing are cut consecutively along the length direction of a section of the cable. The electrode is a typical point-plane geometry and the needle electrode is made of stainless steel with a tip curvature radius of $5 \pm 1 \mu \mathrm{m}$. The ground electrode is $3 \mathrm{~mm}$ away from the needle tip. In order to keep good contact between the needle electrode and the XLPE material, the needle electrode was coated with a very thin layer of polyethylene before being inserted into the sample. The pretreated needle electrode was inserted into the sample while it was heated in a special mould.

\subsection{Experiment set-up}

Figure 2 shows the experiment system for the treeing test of the samples. It consists of a function signal generator (TTi-TG1340 programmable Function Generator) and a wide frequency high voltage amplifier (Trek Model 10/10B), an 
online microscopic digital camera (JVC TK-C1380) and a computer system. The optical bench microscope (LeitzErgolux) was adjusted to a standard magnification level during all stages of tree growth so as to minimize errors due to the influence of magnification. The tree images were captured using the KS400 system developed by Imaging Associates Ltd. To obtain photos with high quality, it is of importance to make the sample surface smooth. In addition, the XLPE samples were also immersed in silicone oil during the experiments in order to enhance the surface insulation and reduce the backlights dispersion from the uneven surface of the sample.

\subsection{Experiment method}

All experiments were performed under the same testing conditions, i.e. $10 \mathrm{kV}$ peak value and $50 \mathrm{~Hz}$ sinewave voltage at room temperature. During the experiment, the photos of electrical trees, the growth rate of electrical trees and other related data were recorded successively. Due to the statistical nature of the propagation characteristics of the electrical trees in XLPE cables, a number of samples with the same type have been tested in order to obtain meaningful experimental results.

\section{Experimental results}

\subsection{Electrical trees in the inner and the outer layers of different voltage rating XLPE cables}

\subsubsection{Electrical trees in the $66 \mathrm{kV} X L P E$ cables}

Structure characteristics. Based on numerous experimental observations, considerable differences in structural and propagation characteristics of electrical trees exist between the inner and the outer layers of the $66 \mathrm{kV}$ XLPE cables insulation. Electrical trees appearing in the inner layer can be divided into five types by structure, i.e. branch-like (figure 3(a)), branch-vine-like (figure 3(b)), branch-pine-like (figures 3(c) and $(d)$ ), branch-bush-like (figure 3(e)) and pure-bush-like (figure $3(f)$ ), all of them are selected as representatives from our experiments. Among the five types, the branch-vine like and the pure branch-like electrical trees possess the lightest colour, indicating that the tree channels are non-conducting. On the other hand, only two types of electrical trees appeared in the outer layer of the cable insulation, namely, pure-bushlike and branch-bush-like trees (figure 4), both of which show a darker colour, implying a semiconducting property of the tree.

Growth characteristics. The growth characteristics of the electrical trees from the inner and the outer layers of the $66 \mathrm{kV}$ XLPE cables insulation are compared in figure 5. Figure 5(a) represents the growth characteristics of the electrical trees shown in figure 3 , while figure $5(b)$ illustrates the growth characteristics of the electrical trees randomly selected in the outer layer of the cable insulation. It is obvious that there is a significant difference in the growth characteristics of electrical trees from the two positions. For the inner layer except the bush-like and the branch-bush-like electrical trees that propagate slowly, other types of inner layer trees approach the ground electrode in about $100 \mathrm{~min}$, which implied that
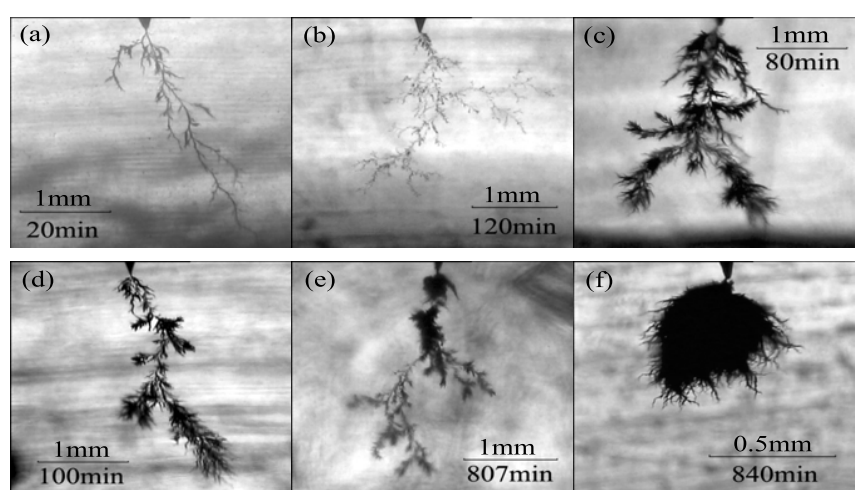

Figure 3. The electrical trees in the inner layer of the $66 \mathrm{kV}$ XLPE cables insulation.

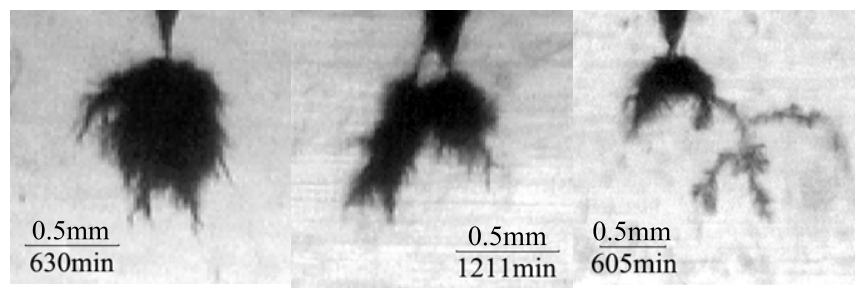

Figure 4. The electrical trees in the outer layer of the $66 \mathrm{kV}$ XLPE cables insulation.

defects, mainly non-ideal morphology, impurities and microhole concentration, must exist in the inner layer. On the other hand, the trees in the outer layer of the cable insulation propagate so slowly that no accelerated growth can be observed even after $1000 \mathrm{~min}$, except one tree that shows an accelerated growth to $2.4 \mathrm{~mm}$ after $600 \mathrm{~min}$, the longest growth time of which can be as long as several days and shows a step-like growth characteristic, implying a more desirable morphology in the outer layer of the XLPE cable insulation.

For the electrical trees in figures $3(e)$ and $(f)$, it is found that no significant growing phenomena can be observed before $600 \mathrm{~min}$ and $840 \mathrm{~min}$, respectively. In order to make the whole graph clear, the horizontal axis of figure $5(a)$ is limited to $120 \mathrm{~min}$. The same principle applies to figure $5(b)$.

\subsubsection{Electrical trees in the $110 \mathrm{kV} X L P E$ cables.}

Structure characteristics. Based on the experimental observations, four types of electrical trees appeared in the inner layer of the $110 \mathrm{kV}$ XLPE cables, namely, branchlike, branch-pine-like, branch-bush-like and pure-bush-like (figure 6(a)) (compared with the electrical trees in the $66 \mathrm{kV}$ cables, the branch-vine like trees were not found in the $110 \mathrm{kV}$ cable insulation). In addition, all the trees here show a dark colour, implying a different propagation mechanism compared with those light colour trees in the $66 \mathrm{kV}$ cable insulation. The electrical trees in the outer layer show three types, branch-pinelike, pine-bush-like and pure-bush-like trees, but no branchlike trees (figure 6(b)). It can be found that the electrical trees which appear in both positions show few differences in structure and all have a darker colour, indicating the deposition of carbon and conducting property of the tree channel. 

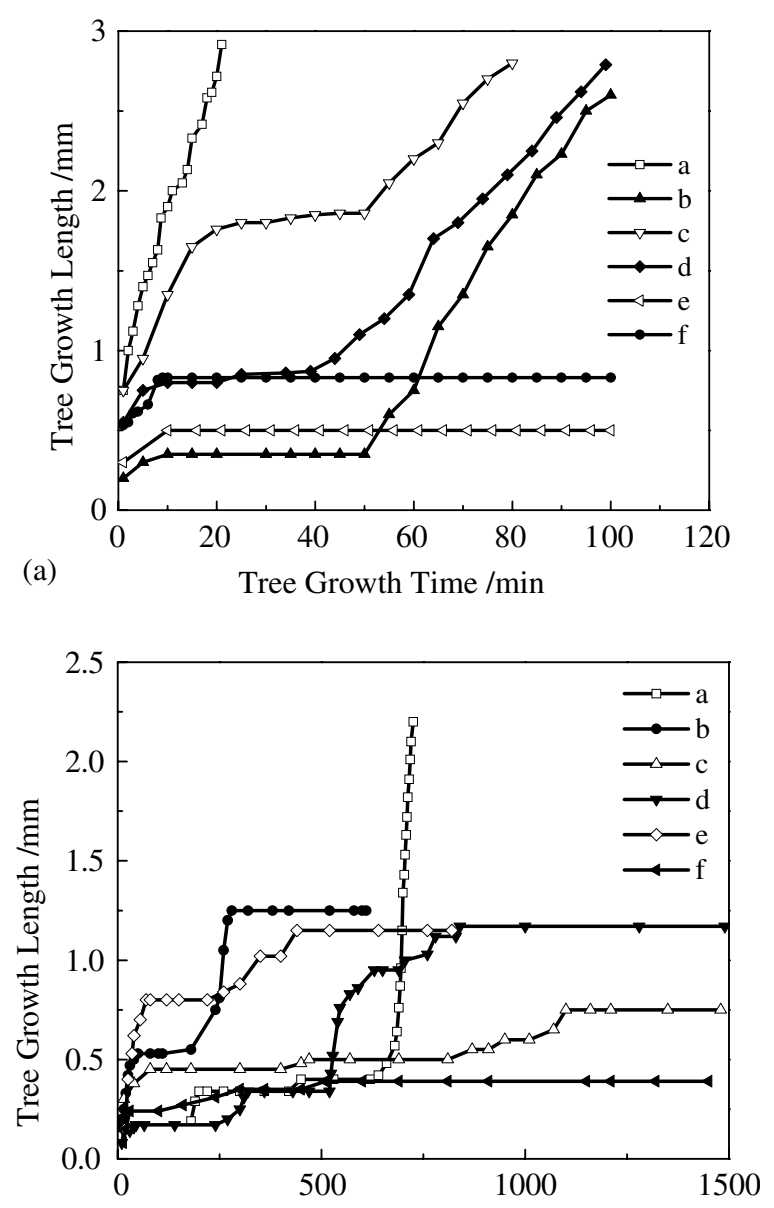

(b)

Tree Growth Time /min

Figure 5. The propagation characteristics of the electrical trees in the inner $(a)$ and the outer $(b)$ layers of the $66 \mathrm{kV}$ XLPE cables insulation.

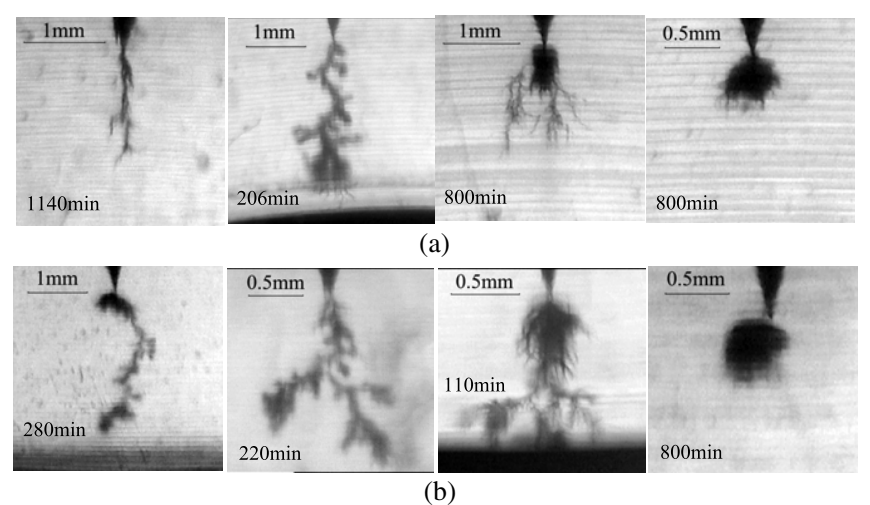

Figure 6. The electrical trees in the inner $(a)$ and the outer $(b)$ layers of the $110 \mathrm{kV}$ XLPE cables insulation.

Growth characteristics. The growth characteristics of the electrical trees grown in the inner and the outer layers of the $110 \mathrm{kV}$ XLPE cables are compared in figure 7. Figures 7(a) and $(b)$ correspond to the growth characteristics of the electrical trees shown in figures 6(a) and $(b)$, respectively, from which it can be found that the propagation characteristics are nearly the same for electrical trees from both positions. In figure 7(a), the electrical trees from the inner layer did not show accelerated
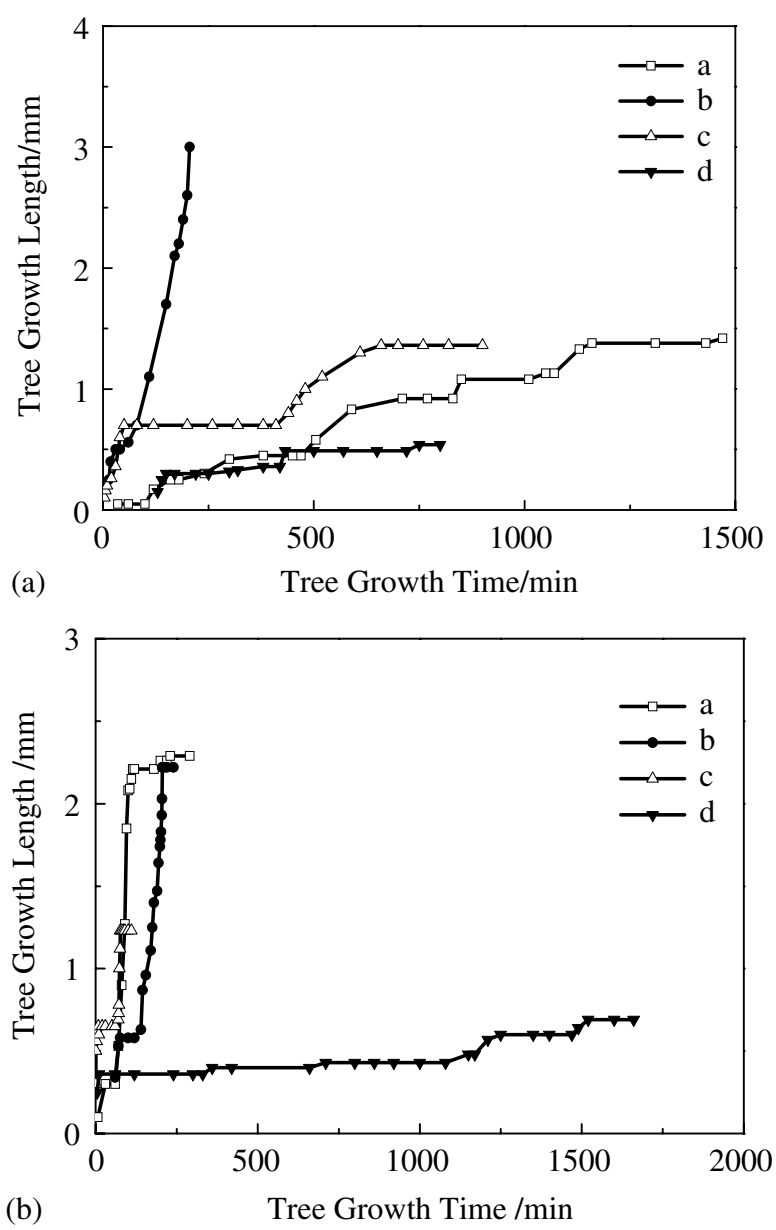

Figure 7. The propagation characteristics of the electrical trees in the inner $(a)$ and the outer $(b)$ layers of the $110 \mathrm{kV}$ XLPE cables insulation.

growth before $800 \mathrm{~min}$, except the branch-pine-like structure that grew quickly and nearly reached the ground electrode after about $200 \mathrm{~min}$; for figure 7(b), electrical trees grown in the outer layer of the cables insulation show an accelerated growth before $300 \mathrm{~min}$, yet only one propagates slowly even after $1600 \mathrm{~min}$. Generally, the treeing rates in the $110 \mathrm{kV}$ cable insulation are much slower than that in the $66 \mathrm{kV}$ XLPE cable.

\subsubsection{Electrical trees in the $220 \mathrm{kV} X L P E$ cables.}

Structure characteristics. The representative structure characteristics of the electrical trees from the inner and the outer layers of the $220 \mathrm{kV}$ XLPE cable insulation are compared in figure 8 . It can be found that only the branch-bush-like and the pure-bush-like trees initiated in both the inner and the outer layers of the cable insulation and with similar structure and darker colour indicating the conducting property of the channel of the tree.

Growth characteristics. The comparisons of growth characteristics of randomly selected electrical trees from the inner and the outer layers of the $220 \mathrm{kV}$ cables insulation are shown in figure 9, from which it can be seen that the growth characteristics from both positions are nearly the same. In addition, 


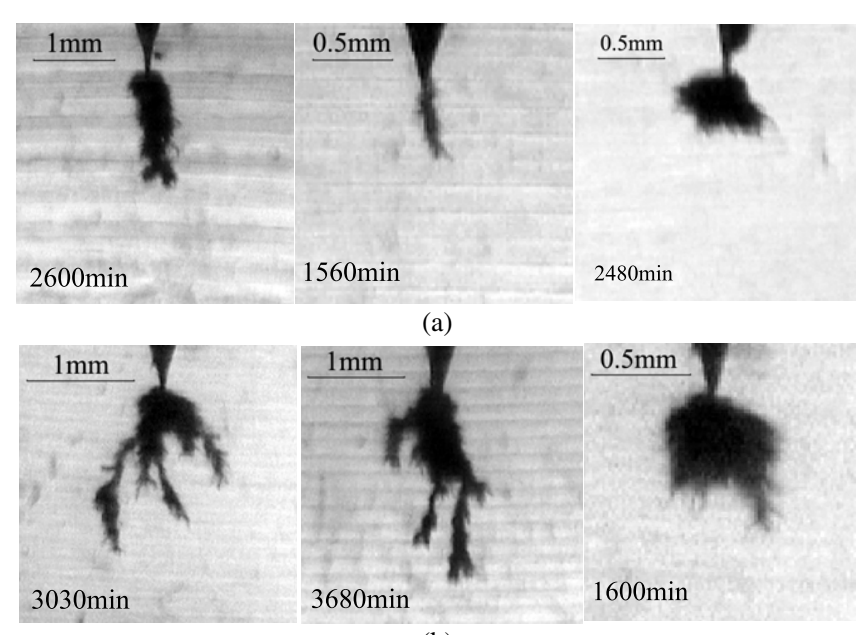

(b)

Figure 8. The electrical trees in the inner $(a)$ and the outer $(b)$ layers of the $220 \mathrm{kV}$ XLPE cables insulation.

only two propagation phases appeared in the whole growth process, and the propagation seems to cease between 2200 and $2500 \mathrm{~min}$, which indicates that the treeing resisting characteristics of the $220 \mathrm{kV}$ cable insulation are much better than the $110 \mathrm{kV}$ and lower voltage rating cables.

\subsubsection{Electrical trees in the $500 \mathrm{kV} X L P E$ cables.}

Structure characteristics. The representative growth types of the electrical trees from the inner and the outer layers of the $500 \mathrm{kV}$ cables are shown in figure 10 , from which it is seen that only the branch-bush-like and the pure-bush-like trees appear just like the case in the $220 \mathrm{kV}$ cable insulation.

Growth characteristics. The comparisons of growth characteristics of the randomly selected electrical trees from the inner and the outer layers of the $500 \mathrm{kV}$ cables are shown in figure 11. It is seen that the growth characteristics from both positions are nearly the same. And nearly all the trees in the inner layer stop propagating after $1500 \mathrm{~min}$, except one electrical tree, which nearly reached the ground electrode after about 2000 min; while all the trees in the outer layer come to a stop after about $2000 \mathrm{~min}$. However, the differences of the treeing resistance between the 220 and the $500 \mathrm{kV}$ cables have not been identified.

\subsection{Statistical analysis of the experiment results}

The initiation and propagation characteristics of the electrical trees in semi-crystalline polymers are somewhat dispersive, which will be further enlarged due to some manufacturing procedures, such as extrusion, cross-linking of $\mathrm{PE}$ and cooling course. Therefore, the statistical method was applied to analyse the characteristics of the electrical trees in the inner and the outer layers of the four different voltage rating XLPE cables. The structure characteristics of the electrical trees are shown in table 2.

From table 2 we can conclude that in the $66 \mathrm{kV}$ XLPE cables, the fast growing trees, such as the branch-like, the
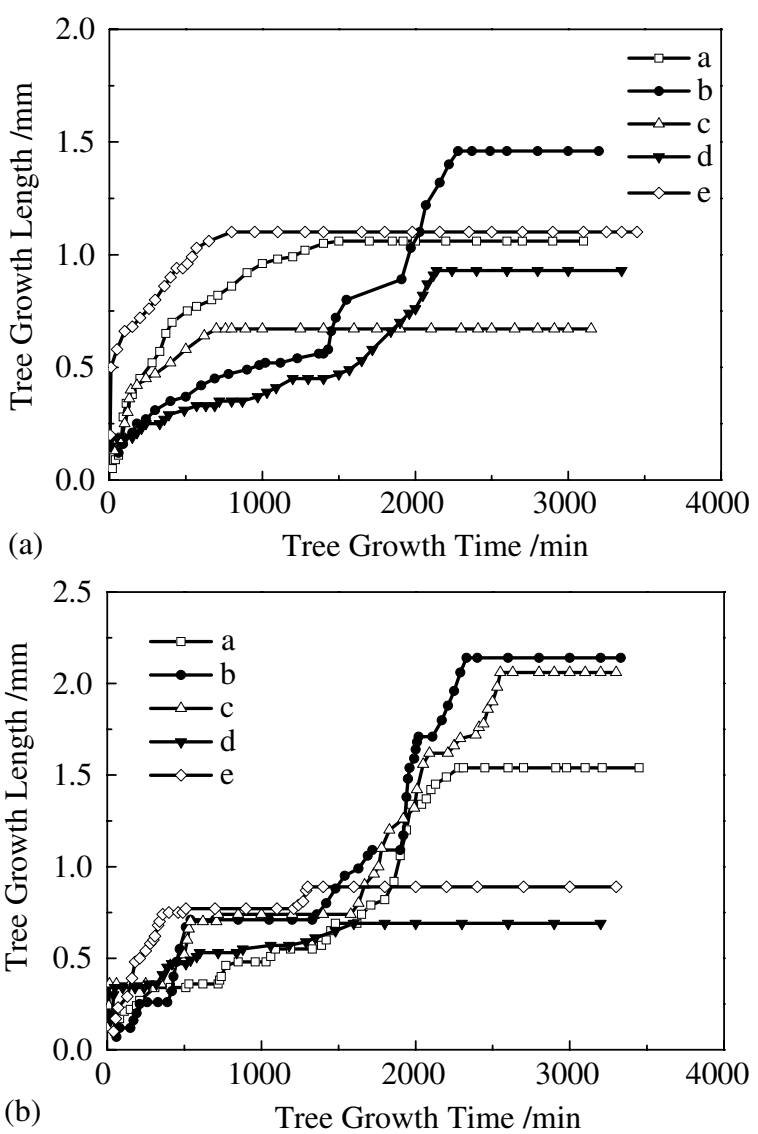

Figure 9. The propagation characteristics of the electrical trees in the inner $(a)$ and the outer $(b)$ layers of the $220 \mathrm{kV}$ XLPE cables insulation.
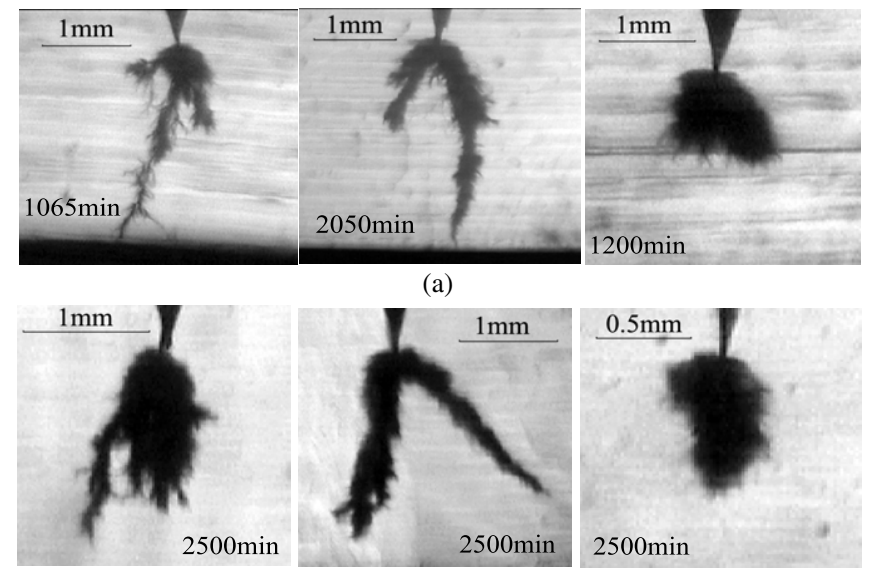

(b)

Figure 10. The electrical trees in the inner $(a)$ and the outer $(b)$ layers of the $500 \mathrm{kV}$ XLPE cables insulation.

branch-pine-like and the branch-vine-like trees, amount to $85 \%$ in the inner layer, while the slowly propagating trees dominate $(80 \%)$ in the outer layer, indicating a considerable difference in the electrical tree structure between the inner and the outer layers of the cable; for the $110 \mathrm{kV}$ XLPE cable, branch-like and mixed-like trees together come up to $40 \%$ and bush-like $60 \%$ in the inner layer, while in the outer layer their proportions are $29 \%$ and $57 \%$, respectively, illustrating that 

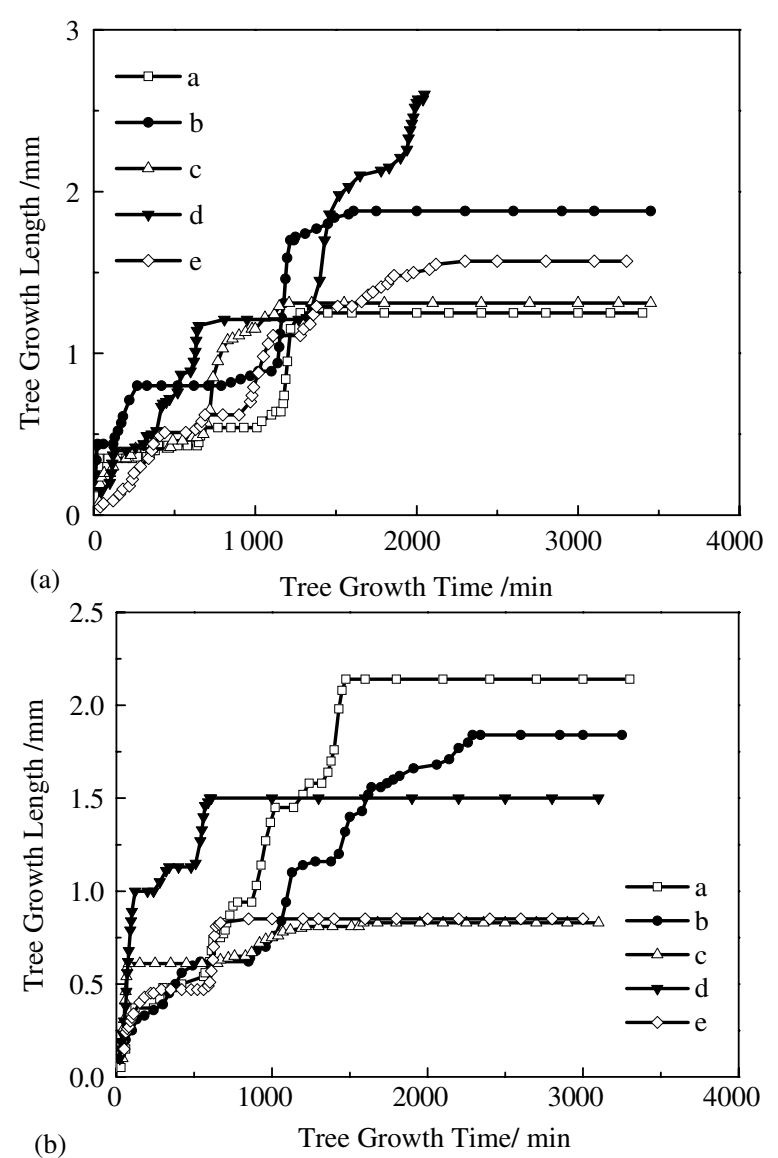

Figure 11. The propagation characteristics of the electrical trees in the inner $(a)$ and the outer $(b)$ layers of the $500 \mathrm{kV}$ XLPE cables insulation.

similar electrical tree structures exist in the inner and the outer layers; for the 220 and $500 \mathrm{kV}$ cables, no distinct differences can be detected from the inner and the outer layers.

The initiation and propagation characteristics are listed in table 3. From table 3, it can be shown that the average initiation time of the electrical trees in both the inner and the outer layers of the $66 \mathrm{kV}$ XLPE cable is the shortest, and the growth rates also differ for the inner layer and the outer layer. The actual growth rates of the trees in the inner layer are much greater than that in the outer layer. This is also true for the other higher voltage rating cable insulation. While, for the $110 \mathrm{kV}$ and above voltage rating cables, the initiation time and growth rate from the inner layer are close to that from the outer layer, and it seems that the higher the voltage rating of the cable, the slower the propagation rate. In the experiment, the growth rates of the bush-like trees are so slow $\left(<0.04 \mathrm{~mm} \mathrm{~h}^{-1}\right)$ that the constructive method is to 'truncate' the observation at some time (>3000 min) after the electrical trees stopped propagation.

\subsection{Crystallinity analysis of the cable insulations}

The crystallinities of the inner and the outer layers for the four different voltage rating XLPE cables insulation are investigated by $\mathrm{X}$-ray diffraction; the results are listed in table 4 .
3.4. Molecule weight and its distribution of the cable insulation materials

Molecule weight and its distribution exert an important influence on the morphology and the physical properties of semi-crystalline polymers [23,24]. The melting and crystallization behaviours of the four different voltage rating XLPE cables insulation are evaluated by DSC. Figure 12 shows the DSC curves of the four different voltage rating cables insulation, and table 5 gives the results of DSC curves and the calculated crystallinity $\left(X_{\mathrm{c}}\right)$. From figure 12 , it can be observed that with higher voltage rating, the melting temperature $\left(T_{\mathrm{m}}\right)$ of the XLPE cable insulation will drop a little bit, indicating a reduction in the molecule weight and a narrowing of the molecular weight distribution of the base polymer material, which in turn weakens the interaction between the large and small molecules, forms dense crystallization centres, increases the crystallinity, narrows the spherulites size distribution, makes the crystallization ideal and enhances the resistance to treeing. From table 5, it is found that the higher voltage rating XLPE cables insulation possesses the largest average crystallinity, implying the narrowest molecular weight distribution of the cables' base polymer material.

\subsection{The purity level of the cable material}

It is commonly believed that under the same production conditions and for the same material, the thicker the insulation layer, the bigger the crystallization difference of the inner and the outer layers due to the different cooling rate between the inner and the outer layers of the insulation, but it does not happen in our experiments. In our experiment, on the contrary, it seems that the resistivity to the electrical trees of the thicker cable is better than that of the thinner cable, which implies that there must be another factor besides crystallinity, which is responsible for the enhanced resistivity to the electrical trees. And it is known that the electrical trees will propagate along the direction of the impurity concentration, so it is suggested that the impurity content for each cable is different, which is proved by TG. Figure 13 contains the enlarged local graphs of TG curves from 500 to $800^{\circ} \mathrm{C}$, from which the remaining fraction after samples being burnt at $800^{\circ} \mathrm{C}$ can be calculated as follows: $66 \mathrm{kV}, 1.31 \%, 100 \mathrm{kV}, 1.13 \%, 220 \mathrm{kV}, 1.05 \%$ and $500 \mathrm{kV}, 0.095 \%$.

\section{Discussions}

The electrical tree follows the path where the material under investigation is locally weakest, i.e. the tree will progress taking into account the local dielectric strength. It has been proposed [20] that the propagation of electrical trees is related to the PDs within the microchannels. Each type of tree is characterized by a particular discharge rate measured.

It has been proposed that the different electrical tree structures and growth characteristics, which appeared in the inner and the outer layers of the $66 \mathrm{kV}$ XLPE cables, are the results of an accumulation of both micro-holes due to non-ideal crystallization and impurities around big spherulites and of the formation of a net-like electrical weak region [22]. Through 
Table 2. The distribution of electrical trees in the inner and the outer layers of different voltage rating cables.

\begin{tabular}{|c|c|c|c|c|c|c|c|}
\hline & & & \multicolumn{5}{|c|}{ The shape of the tree } \\
\hline & & & \multirow[b]{2}{*}{ Branch-like } & \multicolumn{2}{|c|}{ Mixed-like } & \multicolumn{2}{|c|}{ Bush-like } \\
\hline \multicolumn{3}{|c|}{ Position and number } & & branch-vine like & branch-pine like & pure-bush like & branch-bush like \\
\hline \multirow[t]{4}{*}{$\mathrm{A}(66 \mathrm{kV})$} & Inner & Numbers & 5 & 4 & 8 & 2 & 1 \\
\hline & & & 25 & 20 & 40 & 10 & 5 \\
\hline & Outer & Numbers & 0 & 0 & 0 & 8 & 2 \\
\hline & & $\%$ & 0 & 0 & 0 & 80 & 20 \\
\hline \multirow[t]{4}{*}{ B $(110 \mathrm{kV})$} & Inner & Numbers & 2 & 1 & 1 & 6 & 0 \\
\hline & & & 20 & 10 & 10 & 60 & 0 \\
\hline & Outer & Numbers & 0 & 1 & 1 & 4 & 1 \\
\hline & & $\%$ & 0 & 14.3 & 14.3 & 57.1 & 14.3 \\
\hline \multirow[t]{4}{*}{$\mathrm{C}(220 \mathrm{kV})$} & Inner & Numbers & 0 & 0 & 0 & 2 & 6 \\
\hline & & $\%$ & 0 & 0 & 0 & 25 & 75 \\
\hline & Outer & Numbers & 0 & 0 & 0 & 4 & 5 \\
\hline & & $\%$ & 0 & 0 & 0 & 44 & 56 \\
\hline \multirow[t]{4}{*}{$\mathrm{D}(500 \mathrm{kV})$} & Inner & Numbers & 0 & 0 & 0 & 2 & 8 \\
\hline & & & 0 & 0 & 0 & 20 & 80 \\
\hline & Outer & Numbers & 0 & 0 & 0 & 6 & 4 \\
\hline & & $\%$ & 0 & 0 & 0 & 60 & 40 \\
\hline
\end{tabular}

Table 3. The statistical initiation and growth characteristics of the electrical trees in the inner and outer layers of different voltage rating cables.

\begin{tabular}{|c|c|c|c|c|c|}
\hline \multirow[b]{2}{*}{ Type } & \multirow[b]{2}{*}{ Position } & \multicolumn{4}{|c|}{ Item } \\
\hline & & $\begin{array}{l}\text { Average } \\
\text { initiation } \\
\text { time } \\
(\mathrm{min})\end{array}$ & $\begin{array}{l}\text { Average } \\
\text { growth } \\
\text { time } \\
\text { (min) }\end{array}$ & $\begin{array}{l}\text { Average } \\
\text { growth } \\
\text { length } \\
(\mathrm{mm})\end{array}$ & $\begin{array}{l}\text { Average } \\
\text { growth } \\
\text { rate } \\
\left(\mathrm{mm} \mathrm{h}^{-1}\right)\end{array}$ \\
\hline $\begin{array}{l}\text { A } \\
(66 \mathrm{kV})\end{array}$ & $\begin{array}{l}\text { Inner } \\
\text { Outer }\end{array}$ & $\begin{array}{l}121.6 \\
125\end{array}$ & $\begin{array}{l}292.3 \\
>505\end{array}$ & $\begin{array}{l}2.85 \\
1.18\end{array}$ & $\begin{array}{l}0.65 \\
<0.14\end{array}$ \\
\hline $\begin{array}{l}\text { B } \\
(110 \mathrm{kV})\end{array}$ & $\begin{array}{l}\text { Inner } \\
\text { Outer }\end{array}$ & $\begin{array}{l}160.1 \\
180\end{array}$ & $\begin{array}{l}1113.5 \\
>745\end{array}$ & $\begin{array}{l}1.23 \\
1.15\end{array}$ & $\begin{array}{l}0.068 \\
<0.093\end{array}$ \\
\hline $\begin{array}{l}\mathrm{C} \\
(220 \mathrm{kV})\end{array}$ & $\begin{array}{l}\text { Inner } \\
\text { Outer }\end{array}$ & $\begin{array}{l}243.5 \\
220.6\end{array}$ & $\begin{array}{l}1750.6 \\
2314.3\end{array}$ & $\begin{array}{l}1.25 \\
1.56\end{array}$ & $\begin{array}{l}0.045 \\
0.040\end{array}$ \\
\hline $\begin{array}{l}\mathrm{D} \\
(500 \mathrm{kV})\end{array}$ & $\begin{array}{l}\text { Inner } \\
\text { Outer }\end{array}$ & $\begin{array}{l}260.5 \\
289.6\end{array}$ & $\begin{array}{l}2321.5 \\
>2500\end{array}$ & $\begin{array}{l}1.77 \\
1.43\end{array}$ & $\begin{array}{l}0.046 \\
<0.034\end{array}$ \\
\hline
\end{tabular}

the experiments in the inner and the outer layers of the 110 , 220 and $500 \mathrm{kV}$ XLPE cables, no distinct differences appeared in both positions of the thick cable insulation opposite to what we expected initially. On the contrary, it is found that the higher voltage rating XLPE cable insulation has a much better treeing resistance than the lower voltage rating XLPE cable. The underlying reasons can be explained as follows.

\subsection{Crystallization states of the cable insulation}

For the $66 \mathrm{kV}$ XLPE cable insulation, the cut samples are nearly transparent and their photos are distinct, implying large but fewer spherulites in the sample, which has been proved by SEM and polarization microscopy [21]. The morphologies in the inner and the outer layers of the XLPE cables insulation are very different: the spherulites are large but few in the inner layer, while they are small but dense in the outer layer. However, for the $110 \mathrm{kV}$ and above voltage rating XLPE cables insulation, there are no distinct differences in the inner and the outer layers and the samples exhibit a lighter grey colour indicating a crystallization state of densest but small spherulites. The crystallization state with dense but small spherulites can not only reduce the concentration of impurities and micro-holes but also avoid the formation of defective interfaces between the two morphology phases, i.e. the crystal region and the amorphous region. Thus, the crystallization state should be of prime importance to resist treeing in cables insulation.

\subsection{Crystallinity of the cable insulations}

From table 4, it can be concluded that the crystallinity from the outer layer in the same voltage rating cable insulation is a little bigger than that in the inner layer, and the higher the voltage rating, the higher the crystallinity of the cable and fewer differences in crystallinity between the inner and the outer layers. Based on the above study, it is indicated that the structure and growth characteristics of the electrical trees have a close relationship with crystallinity, and the higher the crystallinity, the better the resistivity of the cables insulation to electrical trees; in addition, a crystallinity of at least about $42 \%$ should be reached for producing the ideal resistivity to electrical trees. When the crystallinity is beyond $42 \%$, the structure and growth characteristics of electrical trees from the inner and the outer layers of cables insulation will not be much different, i.e. unaffected by the crystallinity difference between the inner and the outer layers.

\subsection{Molecular weight and its distribution of the cable insulation materials}

The non-isothermal crystallizing dynamic analysis of the four different voltage rating cables insulation is made by DSC to give a further description of the influence of molecule weight and its distribution on electrical trees. Actually, the production process is a somewhat non-isothermal process from melting 
Table 4. The crystallinity of the inner and the outer layers of the four different voltage rating samples.

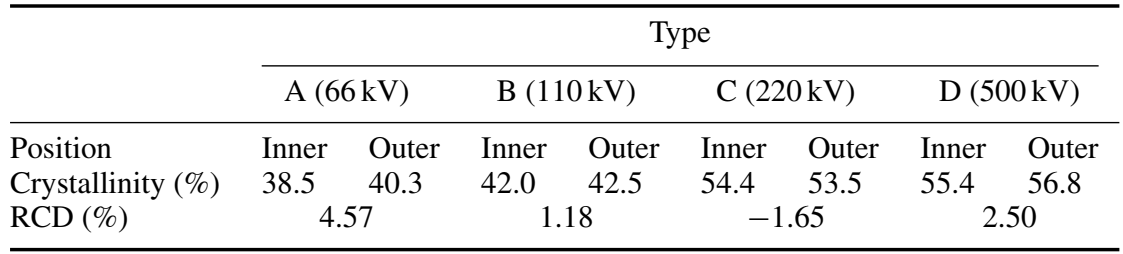

Note: RCD (relative crystallinity difference $)=2\left(X_{\mathrm{o}}-X_{\mathrm{i}}\right) /\left(X_{\mathrm{o}}+X_{\mathrm{i}}\right) ; X_{\mathrm{i}}$ : the

crystallinity of the inner layer; $X_{\mathrm{o}}$ : the crystallinity of the outer layer.

Table 5. The results of the DSC curves.

\begin{tabular}{lcll}
\hline & & $T_{\mathrm{m}}$ & Crystallinity, \\
No & Samples & $\left({ }^{\circ} \mathrm{C}\right)$ & $X_{\mathrm{c}}$ \\
\hline A & $66 \mathrm{kV}$ & 112.93 & 41.76 \\
B & $110 \mathrm{kV}$ & 111.59 & 43.75 \\
C & $220 \mathrm{kV}$ & 110.99 & 52.23 \\
D & $500 \mathrm{kV}$ & 110.63 & 55.69 \\
\hline
\end{tabular}

temperature to room temperature, which can be studied by DSC. Based on isothermal crystallization together with the characteristics of non-isothermal crystallization, we can treat the non-isothermal process of DSC as isothermal only with some corrections. The method proposed by Avrami and Jeziorny [25] is adopted to analyse the obtained DSC curves of the samples from four different voltage rating cables. Avrami equation can be written as

$$
\ln \left[-n\left(1-X_{t}\right)\right]=\ln Z+n \ln t
$$

where $X_{t}$ is the relative crystallinity at time $t, n$ is the Avrami exponent and $Z$ is the crystallization rate constant. $X_{t}$ can be calculated by the following equation:

$$
X_{t}=\frac{\int_{T_{0}}^{T}\left(\mathrm{~d} H_{\mathrm{c}} / \mathrm{d} T\right) \mathrm{d} T}{\int_{T_{0}}^{T_{\infty}}\left(\mathrm{d} H_{\mathrm{c}} / \mathrm{d} T\right) \mathrm{d} T},
$$

where $H_{\mathrm{c}}$ is the heat of crystallization, $T_{0}$ is the starting temperature of crystallization, $T_{\infty}$ is the end temperature of crystallization and $T$ is the crystallization temperature. During the non-isothermal process, time $t$, temperature $T$ and cooling rate have the following relationship:

$$
t=\frac{T_{0}-T}{\Phi}
$$

where $t$ is the crystallization time, $T_{0}$ is the starting temperature of crystallization, $T$ is the crystallization temperature and $\Phi$ is the cooling rate. With the equation above, the $X_{t}-t$ can be obtained, as shown in figure 14.

In figure 13, it can be seen that the crystallization time of the higher voltage rating cables insulation is shorter than that of the lower voltage rating cables insulation, which implies that, after the reducing of the molecular weight and the narrowing of the molecular weight distribution, a shorter crystallization time, a greater crystallization rate, a rise of crystallinity and a uniform spherulite size distribution can be realized. These show that the molecular weight and its distribution of the base polymer material are important to enhance the resistivity to

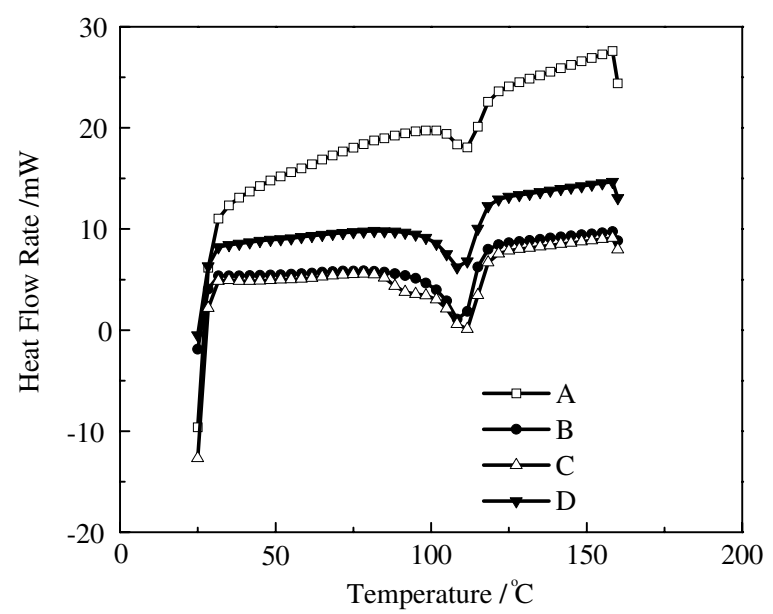

Figure 12. DSC curves of the four different voltage rating cables: (A) $66 \mathrm{kV}$, (B) $110 \mathrm{kV}$, (C) $220 \mathrm{kV}$ and (D) $500 \mathrm{kV}$.

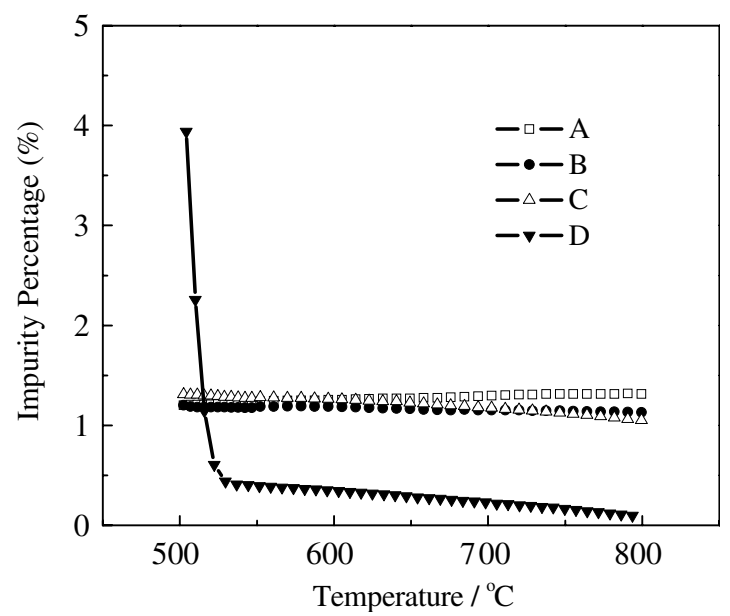

Figure 13. Thermogravimetry curves of the four different voltage rating cables samples: (A) $66 \mathrm{kV}$, (B) $110 \mathrm{kV}$, (C) $220 \mathrm{kV}$ and (D) $500 \mathrm{kV}$.

treeing. On the whole, the higher the voltage rating of the cables, the stricter the demands on the base polymer material will be.

\subsection{Purity level of the cable material}

From figure 13, obviously, the higher the voltage rating of the cables insulation, the purer the base polymer materials, which indicates that impurities as well as high crystallinity are two key factors for XLPE cables insulation to enhance the resistivity to treeing. 


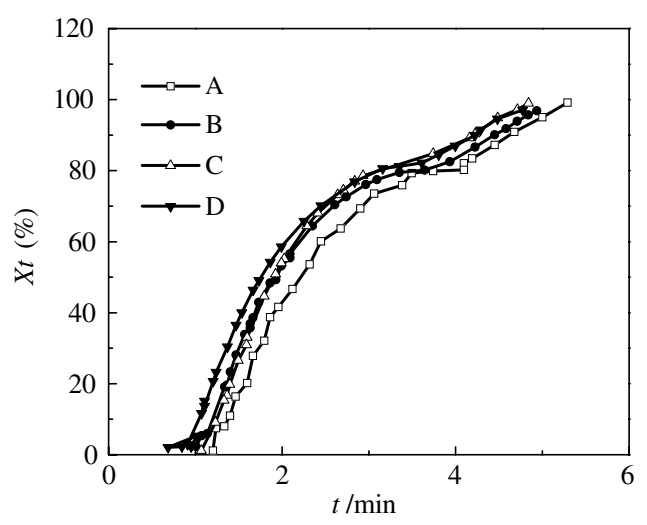

Figure 14. $X_{t}-t$ plots of the four different voltage rating cables samples: (A) $66 \mathrm{kV}$, (B) $110 \mathrm{kV}$, (C) $220 \mathrm{kV}$ and (D) $500 \mathrm{kV}$

\subsection{Synergetic effect}

It is found in the experiment that the ideal initiation and growth conditions for electrical trees are low crystallinity, big spherulites and high impurity level. During the formation of non-uniform big spherulites, if the impurity level is high, the 'synergetic' effect takes place that will drive the impurities to concentrate on the surface of spherulites leading to a netlike insulation weak region, in which the electrical trees will initiate and grow easily. This combined effect, big spherulites cooperating with impurities, will exert far more influence on the electrical trees than the single effect induced by either big spherulites or impurities (e.g. impurities in absolute amorphous polymers). Thus, inhibiting big spherulites, enhancing crystallinity and purity level of the base polymer material, employing the super-clean production technique and proper post-treatment are the ways to develop higher voltage rating cables.

\section{Conclusions}

The initiation and growth of electrical trees in four different voltage rating XLPE power cables have been investigated (the $66 \mathrm{kV}$ rating cable is from UK, the others from China). The following conclusions may be drawn.

Under the same experiment conditions, the structure and propagation characteristics of the electrical trees in the inner layer of the $66 \mathrm{kV}$ cables are different from that in the outer layer, and the growth rate of the electrical trees in the inner layer is higher than that in the outer layer. The non-uniform crystallization between the inner layer and the outer layer is responsible for the difference and there exist big spherulites and more impurities in the inner layer. However, for the $110 \mathrm{kV}$ and above voltage rating XLPE cables insulation, the narrower molecular weight distribution and lower impurity content have been proved, so they have a higher and more uniform crystallinity which will enhance the resistance to electrical treeing.

The molecular weight and its distribution of the base PE material are the prime factors that affect the crystallinity. A narrower molecular weight distribution will lead to a higher crystallinity and more uniform small spherulites.
In the initiation and propagation processes of the electrical trees, big spherulites will cooperate with impurities, termed as the 'synergetic effect', which is obvious when the impurity content is more than $1.13 \%$ and crystallinity is less than $42 \%$. From a practical point of view, to enhance the resistance to electrical treeing in the XLPE cables insulation, it is important to consider these two factors first and then control molecular weight and its distribution and the purity level of the base materials.

\section{Acknowledgment}

The authors wish to thank the National Outstanding Young Investigator Grant of China under Projects No 50625721 and the National Natural Science Foundation of China under Projects No 50577052.

\section{References}

[1] Laurent C, Mayoux C and Noel S 1983 Dielectric breakdown of polyethylene in divergent field: role of dissolved gases and electroluminescence J. Appl. Phys. 541532

[2] Laurent C, Mayoux C and Noel S 1985 Mechanisms of electroluminescence during aging of polyethylene J. Appl. Phys. 584346

[3] Gu W Y, Laurent C and Mayoux C 1986 Characteristics of discharges inside simulated tree channels under impulse voltage J. Phys. D: Appl. Phys. 19 2197-207

[4] Dodd S J 2003 A deterministic model for the growth of non-conducting electrical tree structures J. Phys. D: Appl. Phys. 36 129-41

[5] Noskov M D, Sack M, Malinovski A S and Schwab A J 2001 Measurement and simulation of electrical tree growth and partial discharge activity in epoxy resin J. Phys. D: Appl. Phys. 34 1389-98

[6] Champion J V and Dodd S J 2001 Simulation of partial discharges in conducting and non-conducting electrical tree structures J. Phys. D: Appl. Phys. 34 1235-42

[7] Champion J V and Dodd S J 1998 An approach to the modelling of partial discharges in electrical trees J. Phys. D: Appl. Phys. 31 2305-14

[8] Wu K, Suzuoki Y, Mizutani T and Xie H K 2000 Model for partial discharges associated with treeing breakdown: I. PDs in tree channels J. Phys. D: Appl. Phys. 33 1197-201

[9] Wu K, Suzuoki Y, Mizutani T and Xie H K 2000 Model for partial discharges associated with treeing breakdown: II. tree growth affected by PDs J. Phys. D: Appl. Phys. 33 1202-8

[10] Wu K, Suzuoki Y, Mizutani T and Xie H K 2000 Model for partial discharges associated with treeing breakdown: III. PD extinction and re-growth of tree J. Phys. D: Appl. Phys. 33 1209-18

[11] Champion J V, Dodd S J and Stevenst G C 1994 An examination of the effect of mechanical stress on electrical breakdown in synthetic resin insulators J. Phys. D: Appl. Phys. 27 142-7

[12] Champion J V and Dodd S J 1999 An assessment of the effect of externally applied mechanical stress and water absorption on the electrical tree growth behaviour in glassy epoxy resins J. Phys. D: Appl. Phys. 32 305-16

[13] Barclayt A L, Sweeney P J, Dissado L A and Stevenst G C 1990 Stochastic modeling of electrical treeing: fractal and statistical characteristics J. Phys. D: Appl. Phys. 23 1536-45

[14] Bamji S S, Bulinski A T, Suzuki H, Matsuki M and lwata Z 1993 Luminescence in crosslinked polyethylene at elevated temperatures J. Appl. Phys. 74 5149-53 
[15] Ishibashi A, Kawai T, Nakagawa S, Muto H, Katakai S, Hirotsu K and Nakatsuka T 1998 A study of treeing phenomena in the development of insulation for $500 \mathrm{kV}$ XLPE cables IEEE Trans. Elec. Insul. 5 695-706

[16] Fothergill J C 1991 Filamentary electromechanical breakdown IEEE Trans. Elec. Insul. 26 1124-9

[17] Harlin A, Shuvalov M, Ovsienko V and Juhanoja J 2002 Insulation morphology effects on the electrical treeing resistance IEEE Trans. Elec. Insul. 9 401-5

[18] Lee S Y, Kim Y H, Lee I H and Amyot N 2001 Influence of internal residual mechanical stresses on local dielectric strength of EHV extruded XLPE cables Electrical Insulation Conf. and Electrical Manufacturing \& Coil Winding Conf. Cincinnati, $O H$ vol 16-18, pp 345-8

[19] Ildstad E and Hagen S T 1992 Electrical treeing and breakdown of mechanically strained XLPE cable insulation Electrical Insulation Conf. Record of the IEEE Int. Symp. (Baltimore, MD) vol 7-10, pp 135-9
[20] Laurent C and Mayoux C 1980 Analysis of the propagation of electrical treeing using optical andelectrical methods IEEE Trans. Electr. Insul. 15 33-42

[21] Zheng X Q and Chen G 2008 Propagation mechanism of electrical tree in XLPE cable insulation by investigating a double electrical tree structure IEEE Trans. Elec. Insul. 15 800-7

[22] Zheng X Q, Xie A S and Li S T 2007 The electrical trees that in inner and outer layer of XLPE cable insulation Acta Phys. Sin. 56 5494-8

[23] Lei H, Xu T and Yu J 2004 The effect of molecular weight and its distribution on crystalline morphology of PP materials Polym. Mater. Sci. Eng. 20 166-73

[24] Li W D and Yang G S 1996 Effect of molecular weight and molecular weight distribution on mechanical properties and crystallization of isotactic polypropylene Polym. Mater. Sci. Eng. 12 41-6

[25] Jeziorny A 1978 Polymer 19 1142-244 